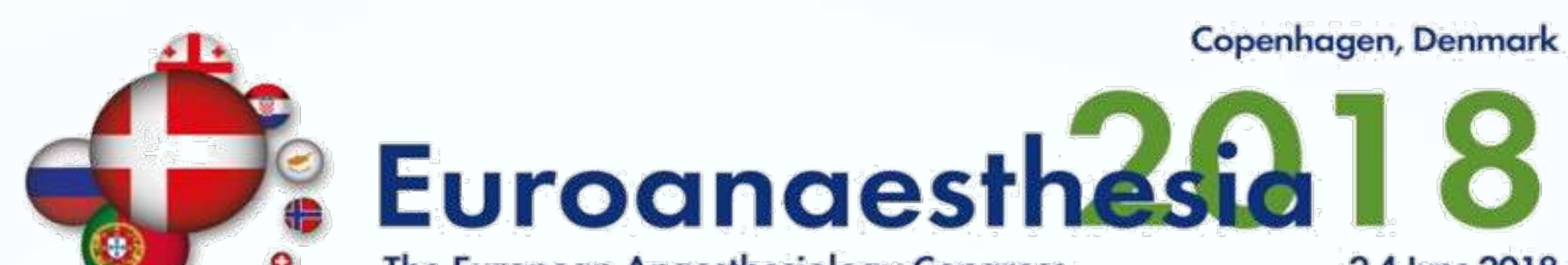

\title{
Peribulbar block vs. general anaesthesia for corneal transplantation: Analgesic requirements and pain control
}

Gonçalves G., Xavier J., Sá J., Cavaleiro C., Ferreira L., Machado H.

Centro Hospitalar do Porto, Department of Anaesthesiology and Intensive Care, Porto, Portugal

\section{BACKGROUND}

- Effective anaesthesia for corneal transplantation (CT) can be achieved with general (GA) or regional anaesthesia (RA)

- CT has usually been performed under GA

- We believe that PBB can achieve effective surgical anaesthesia and postoperative analgesia with lower analgesic requirements and similar surgical conditions, compared to GA

\section{GOAL OF THE STUDY}

To compare the analgesic efficacy of PBB and GA for CT.

\section{Materials AND Methods}

- Prospective observational study

- Between August and November 2017

- Statistical tests: Chi-squared and Mann-Whitney U

- Statistical significance: $p<0.05$

\section{RESULTS AND Discussion}

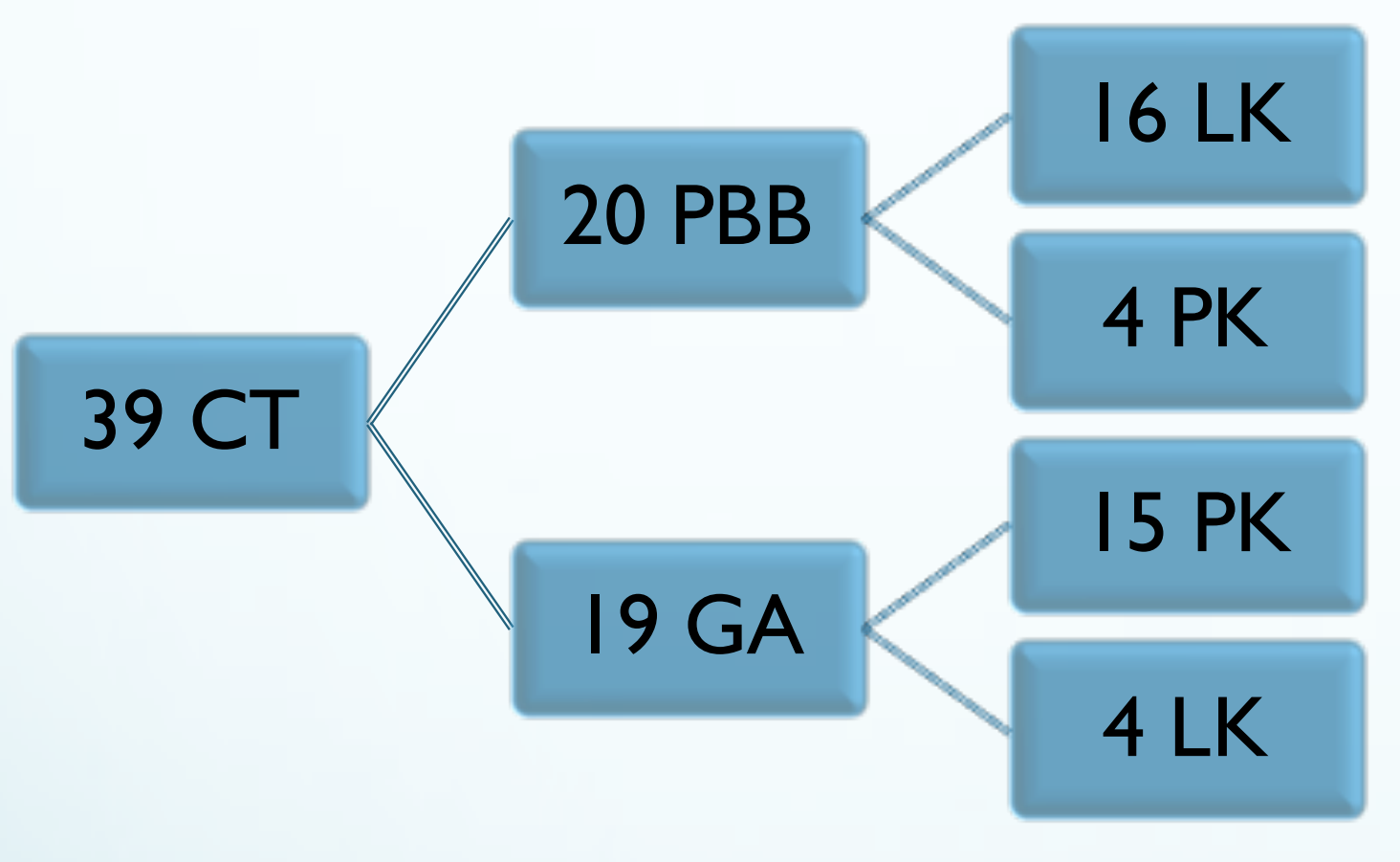

- No difference in pain score on PACU arrival

- Trend towards lower pain scores 30 minutes after surgery in the PBB group $(p=0.077)$.

- No difference was observed regarding the surgeon's opinion of surgical conditions.

\section{CONCLUSIONS}

CT under PBB provided comparable pain control and surgical conditions to GA, with much lower systemic analgesic requirements.
Data collected:

$\checkmark$ Age, gender, height, weight

$\checkmark$ ASA physical score

$\checkmark$ Procedure and anaesthesia lengths

$\checkmark$ Analgesic drug administration

$\checkmark$ VAS pain score (PACU arrival and 30 minutes after surgery)

$\checkmark$ Postoperative analgesic needs

$\checkmark$ Opinion of the ophthalmologist

\begin{tabular}{lcccc}
\hline & GA & PBB & $p$ \\
\hline Age (average, years) & $58(23-84)$ & $71(48-94)$ & 0,057 \\
\hline BMI (average, kg/m²) & $27,95 \pm 4,56$ & $26,6 \pm 5,47$ & 0,194 \\
& F & $11(57,9 \%)$ & $11(55 \%)$ & 0,855 \\
Gender & M & $8(42,1 \%)$ & $9(45 \%)$ & \\
& 1 & - & $1(5 \%)$ & \\
\hline ASA-PS & 2 & $13(68,4 \%)$ & $12(60 \%)$ & 0,579 \\
\hline Fentanyl (average dose, $\mu$ g) & $154 \pm 81$ & $48 \pm 38$ & $<0,001$ \\
\hline Paracetamol (n. of patients) & $18(94,7 \%)$ & $10(50 \%)$ & 0,002 \\
\hline Tramadol (n. of patients) & $10(52,6 \%)$ & $2(10 \%)$ & 0,004 \\
\hline AINE (n. of patients) & $11(57,9 \%)$ & $2(10 \%)$ & 0,002 \\
\hline Morphine (n. of patients) & $1(5,3 \%)$ & 0 & 0,299 \\
\hline
\end{tabular}

